\title{
Editorial
}

\section{Ranking Fuzzy Numbers and Its Extensions}

\author{
Tofigh Allahviranloo, ${ }^{1}$ Ronald R. Yager, ${ }^{2}$ \\ Saeid Abbasbandy, ${ }^{3}$ and Gozde Ulutagay ${ }^{4}$ \\ ${ }^{1}$ Department of Electronics and Communications, Faculty of Engineering, Izmir University, \\ 35350 Izmir, Turkey \\ ${ }^{2}$ Department of Computational Intelligence, Iona College, New York, NY 10801, USA \\ ${ }^{3}$ Department of Mathematics, IKIU, Ghazvin 34149-16818, Iran \\ ${ }^{4}$ Department of Industrial Engineering, Faculty of Engineering, Izmir University, \\ 35350 Izmir, Turkey
}

Correspondence should be addressed to Tofigh Allahviranloo; tofigh@allahviranloo.com

Received 27 August 2013; Accepted 27 August 2013

Copyright (c) 2013 Tofigh Allahviranloo et al. This is an open access article distributed under the Creative Commons Attribution License, which permits unrestricted use, distribution, and reproduction in any medium, provided the original work is properly cited.

Ranking fuzzy numbers plays a prominent role in management, engineering, and basic sciences. Fuzzy numbers are represented by a membership function, and despite the real numbers that can be linearly ordered, fuzzy numbers might overlap with each other; thus, their ordering seems impossible or very difficult. Varieties of methods have been proposed for ranking fuzzy numbers in the recent years. Due to nonintuitive and nondiscriminating results of these methods that cause inconsistency in outputs, generalization of them is limited and there are some extenuations associated with them. Some of the ranking methods use defuzzification methods, while others are based on the membership function or metric distance methods. This issue's papers study the following areas.

(i) Similarity: it is being used in the approximation theory.

(ii) Ordering: it is used for ordering fuzzy numbers and quantities.

(iii) Risk analysis: it is used in management science.

(iv) Optimization: it is applied in management and applied science. (v) Fuzzy differential equation: the nonequality case in this equations can be ordered.

(vi) Fuzzy clustering: it is used in intelligent systems.

Tofigh Allahviranloo Ronald R. Yager Saeid Abbasbandy Gozde Ulutagay 


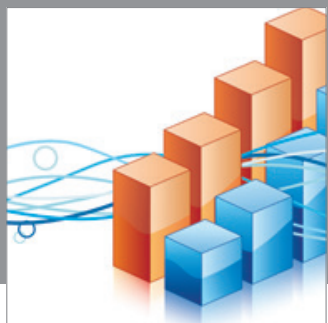

Advances in

Operations Research

mansans

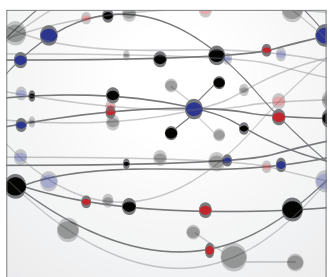

The Scientific World Journal
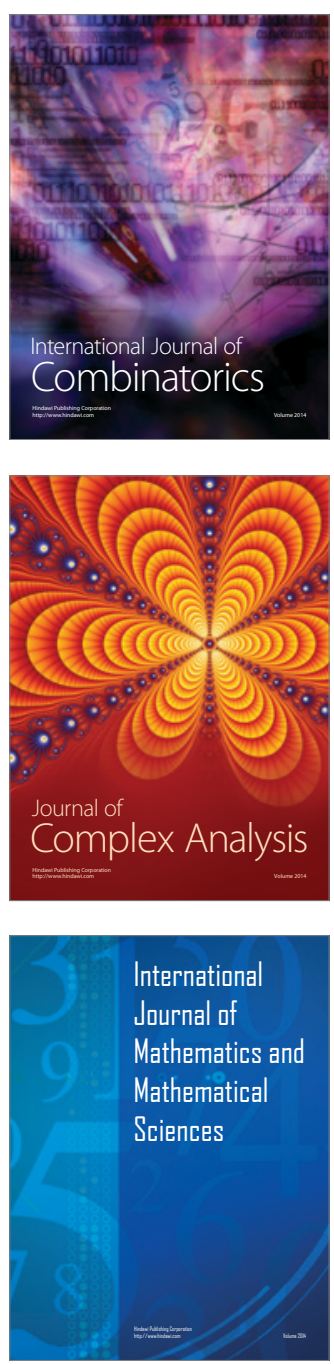
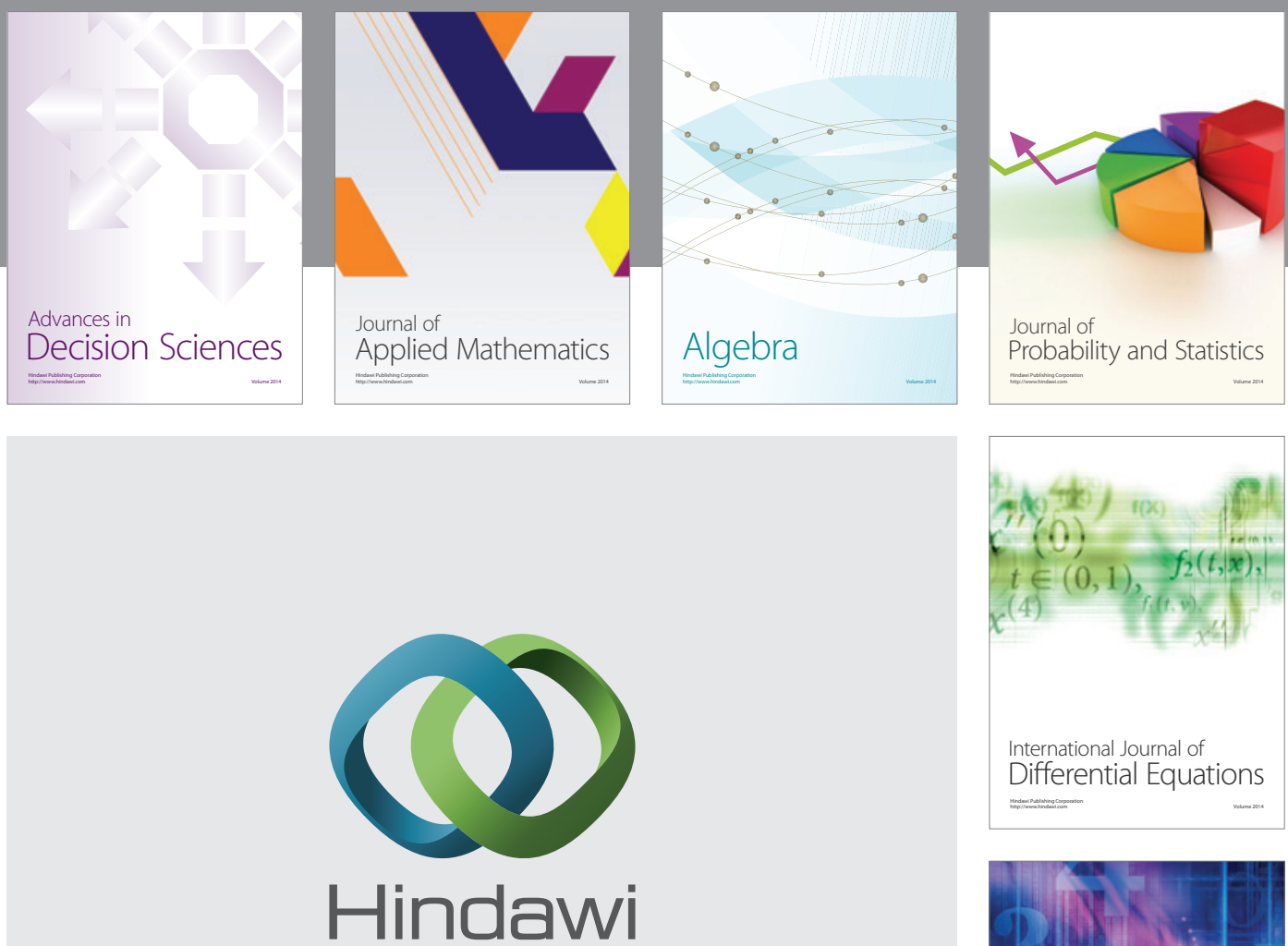

Submit your manuscripts at http://www.hindawi.com
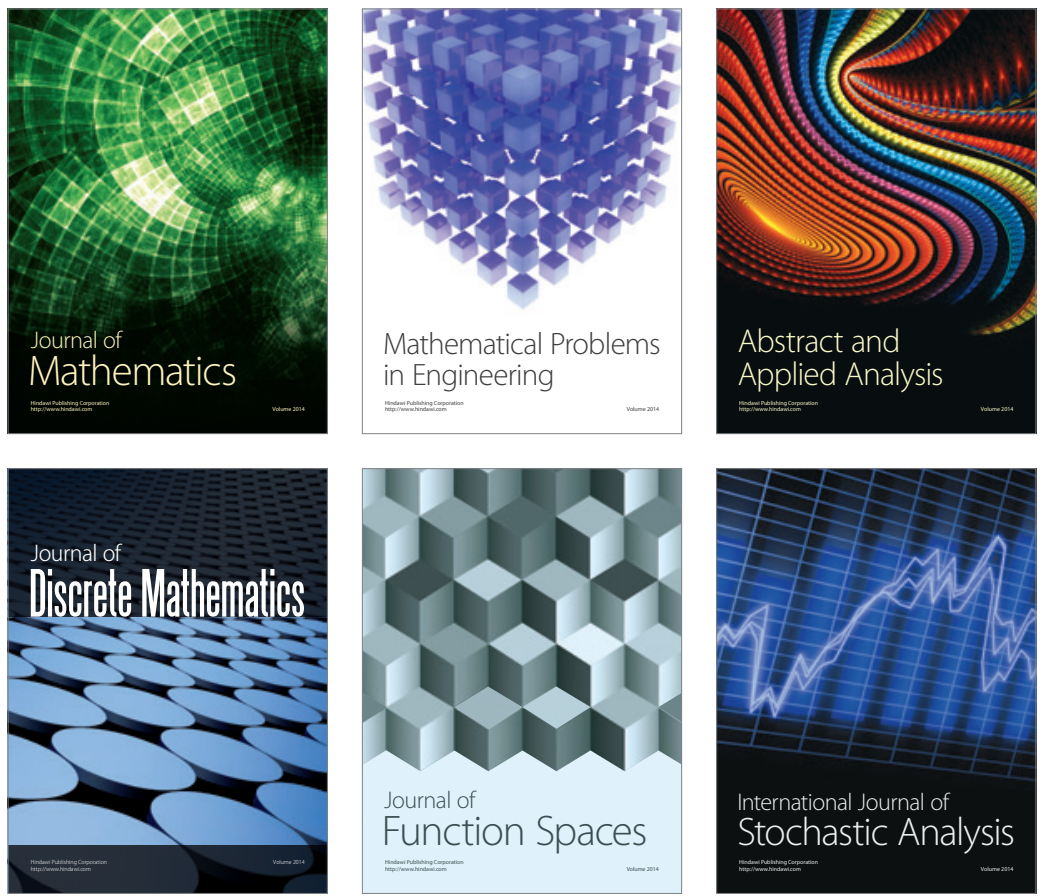

Journal of

Function Spaces

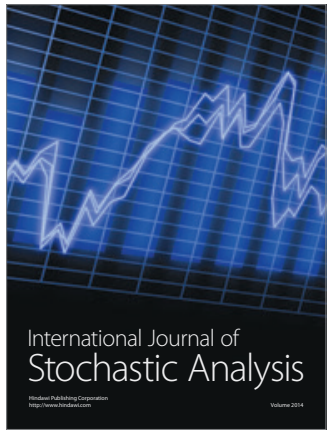

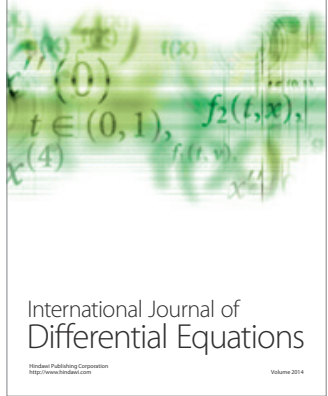
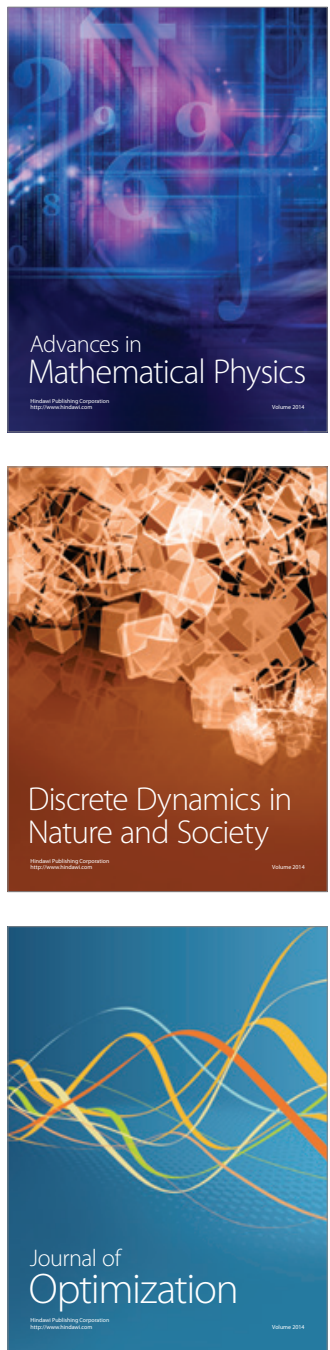